\title{
Surgical options after Fontan failure
}

\section{van Melle, Joost $P$.}

2016-07

van Melle , J P , Wolff , D , Hoerer , J , Belli , E, Meyns , B , Padalino , M , Lindberg , H , Jacobs , J P , Mattila , I P , Berggren , H , Berger , R M F, Pretre , R , Hazekamp , M G , Helvind, M , Nosal , M , Tlaskal , T , Rubay , J , Lazarov , S , Kadner , A , Hraska , V , Fragata , J , Pozzi , M , Sarris , G , Michielon , G , di Carlo , D \& Ebels , T 2016 , ' Surgical options after Fontan failure ' , Heart , vol. 102 , no. 14 , pp. 1127-1133 . https://doi.org/10.1136/heartjnl-2015-309235

http://hdl.handle.net/10138/224075

https://doi.org/10.1136/heartjnl-2015-309235

publishedVersion

Downloaded from Helda, University of Helsinki institutional repository.

This is an electronic reprint of the original article.

This reprint may differ from the original in pagination and typographic detail.

Please cite the original version. 


\title{
Surgical options after Fontan failure
}

\author{
Joost P van Melle, ${ }^{1}$ Djoeke Wolff, ${ }^{2}$ Jürgen Hörer, ${ }^{3}$ Emre Belli, ${ }^{4}$ Bart Meyns, ${ }^{5}$ \\ Massimo Padalino, ${ }^{6}$ Harald Lindberg, ${ }^{7}$ Jeffrey $P$ Jacobs, ${ }^{8,9}{ }^{1 / k k a} \mathrm{P}$ Mattila, ${ }^{10}$ \\ Håkan Berggren, ${ }^{11}$ Rolf M F Berger, ${ }^{2}$ Rene Prêtre, ${ }^{12}$ Mark G Hazekamp, ${ }^{13,14}$ \\ Morten Helvind, ${ }^{15}$ Matej Nosál, ${ }^{16}$ Tomas Tlaskal, ${ }^{17}$ Jean Rubay, ${ }^{18}$ Stojan Lazarov, ${ }^{19}$ \\ Alexander Kadner, ${ }^{20}$ Viktor Hraska, ${ }^{21}$ José Fragata, ${ }^{22}$ Marco Pozzi, ${ }^{23}$ \\ George Sarris, $^{24,25}$ Guido Michielon, ${ }^{26}$ Duccio di Carlo, ${ }^{27}$ Tjark Ebels $^{26}$
}

\begin{abstract}
- Additional material is published online only. To view please visit the journal online (http://dx.doi.org/10.1136/ heartjnl-2015-309235).

For numbered affiliations see end of article.

\section{Correspondence to} Dr Joost $P$ van Melle, University Medical Center Groningen, University of Groningen, P.O.B. 30.001, Groningen 9700 RB,

The Netherlands; j.p.van.melle@umcg.nl
\end{abstract}

Received 24 December 2015 Revised 29 February 2016 Accepted 3 March 2016 Published Online First 13 April 2016

\section{SLinked}

- http://dx.doi.org/10.1136/ heartjnl-2016-309587

\section{CrossMark}

To cite: van Melle JP, Wolff $D$, Hörer J, et al. Heart 2016:102:1127-1133.

\section{ABSTRACT}

Objective The objective of this European multicenter study was to report surgical outcomes of Fontan takedown, Fontan conversion and heart transplantation (HTX) for failing Fontan patients in terms of all-cause mortality and (re-)HTX.

Methods A retrospective international study was conducted by the European Congenital Heart Surgeons Association among 22 member centres. Outcome of surgery to address failing Fontan was collected in 225 patients among which were patients with Fontan takedown $(n=38 ; 17 \%)$, Fontan conversion $(n=137$; $61 \%)$ or HTX ( $n=50 ; 22 \%)$.

Results The most prevalent indication for failing Fontan surgery was arrhythmia (43.6\%), but indications differed across the surgical groups $(p<0.001)$. Fontan takedown was mostly performed in the early postoperative phase after Fontan completion, while Fontan conversion and HTX were mainly treatment options for late failure. Early (30 days) mortality was high for Fontan takedown (ie, 26\%). Median follow-up was 5.9 years (range 0-23.7 years). The combined end point mortality/HTX was reached in $44.7 \%$ of the Fontan takedown patients, in $26.3 \%$ of the Fontan conversion patients and in $34.0 \%$ of the HTX patients, respectively (log rank $\mathrm{p}=0.08)$. Survival analysis showed no difference between Fontan conversion and HTX ( $p=0.13)$, but their ventricular function differed significantly. In patients who underwent Fontan conversion or HTX ventricular systolic dysfunction appeared to be the strongest predictor of mortality or (re-)HTX. Patients with valveless atriopulmonary connection (APC) take more advantage of Fontan conversion than patients with a valvecontaining APC $(p=0.04)$.

Conclusions Takedown surgery for failing Fontan is mostly performed in the early postoperative phase, with a high risk of mortality. There is no difference in survival after Fontan conversion or HTX.

\section{INTRODUCTION}

For patients with various forms of functional univentricular congenital heart defects (CHD), a direct routing of the systemic return to the pulmonary arteries, in the absence of a pulmonary cardiac chamber, has been adopted as the usual surgical option. Since its invention, independently by both Fontan and Baudet ${ }^{1}$ and Kreutzer et $a l^{2}$ in 1971 and 1973 in France and Argentina, respectively, a large series of surgical improvements and refinements have resulted in a better outcome for these patients. ${ }^{3}$ Nowadays, it can be estimated that about 2.3:10 000 newborns with CHD are evaluated for the staged Fontan pathway, and of these, the majority reach adulthood. ${ }^{4}$

However, a growing body of evidence reveals that life-threatening complications inevitably occur from adolescence onwards. Therefore, the term 'Failing Fontan' has been introduced to refer to a clinical situation with major rhythm disturbances refractory to maximal medical therapy, thrombotic events in the Fontan circuit, protein losing enteropathy (PLE), plastic bronchitis, chronic oedema and ascites, cirrhosis and hepatic malignancy ${ }^{5}$ or ventricular failure. ${ }^{6} 7$ The surgical solutions for patients with failing Fontan have evolved over time. Nowadays, three surgical options are embraced worldwide: Fontan takedown, ${ }^{8}$ Fontan conversion to an energetically more favourable connection (ie, lateral tunnel (LT) ${ }^{9}$ or extracardiac conduit ${ }^{10}$ ) and heart transplantation ${ }^{11} 12$ (HTX). These high-risk procedures have been advocated based on institutional experience with limited data and nonuniform midterm results. The objective of this international multicenter study is to perform a comprehensive analysis of the midterm surgical outcome for failing Fontan surgery, in order to suggest an effective decision-making process for this growing subset of critically ill patients.

\section{METHODS}

\section{Patients}

Patients who underwent Fontan surgery between 1971 and 31 December 2012 for the clinical syndrome of 'Failing Fontan' were eligible for inclusion in the F2 study. Three surgical options were taken into account: (1) Fontan takedown, (2) Fontan conversion and (3) HTX. Fontan takedown was defined as a takedown of a completed Fontan circulation to a superior cavopulmonary connection (bidirectional Glenn (BDG)) or a systemic-topulmonary arterial shunt (eg, Blalock-Taussig shunt) or both. Fontan conversion included a conversion from a traditional Fontan circulation (eg, an atriopulmonary connection (APC) with or without valve, or a Björk modification) to a LT or extracardiac conduit (EC), and conversion from a LT to an EC. Revisions (ie, major surgery to modify a 
suboptimal Fontan circuit without complete Fontan conversion) were excluded from analysis. Patients were identified within participating units of the European Congenital Heart Surgeons Association, with the use of local registries searching for Fontan patients or reviews of hospital patient charts. The University Medical Center Groningen coordinated the study, collected the data, maintained the database and performed all the data analyses. Review of medical records was approved by each local committee on clinical investigation. Individual patients were not identifiable, and the need for patient consent was waived.

\section{Patient variables}

The collected data on patient characteristics included primary anatomical diagnosis, relevant cardiovascular comorbidity, surgical interventions before the initial Fontan procedure, important prognostic patient variables previously described in Fontan research, that is, New York Heart Association (NYHA) functional class $(\mathrm{FC})^{13}$ and cardiac function (ie, systolic ventricular function $^{14}$ and atrioventricular valve regurgitation ${ }^{15}$ ) and preoperative cardiac medication use. Furthermore, the indications which led to failing Fontan surgery were classified as deteriorating FC, refractoriness of arrhythmia treatment, thrombus/ emboli, severe right atrial (RA) dilatation, hemodynamic important obstruction in Fontan circuit, pulmonary venous obstruction, PLE, atrioventricular valve surgery, Fontan baffle leak or subaortic stenosis. More than one indication was possible within the same patient. Hemodynamic data (ie, RA pressure) from latest heart catheterisation were available for 170 patients. Finally, the following variables regarding failing Fontan surgery were documented: aortic cross clamp time, cardiopulmonary bypass time, duration of circulatory arrest, concomitant surgical interventions and postoperative duration of mechanical ventilation as well as hospital stay. Ventricular assist devices as a bridge to transplant were documented.

\section{Statistical analysis}

Data were analysed with the use of SPSS V.20.0 for Windows. Continuous data were reported as mean $\pm S D$ or median (IQR) and categorical data as number of patients (percentage of total, within the surgical arm). The primary end point was all-cause mortality or (re-)HTX. Secondary outcomes included early mortality (within 30 days of failing Fontan surgery) and late mortality. The last follow-up ended at 1 January 2014. Patients' data were censored at the time of last contact. When appropriate, the primary end point was analysed according to the intention-to-treat principle. Thus, patients with a cross-over in surgical strategy (eg, Fontan conversion and during follow-up HTX) were analysed according to their initial intervention.

Baseline characteristics across the three groups were compared using one-way analysis of variance or $\chi^{2}$ analyses, depending on the variable of interest. For other comparisons, the Student's $t$ test for continuous measures and the $\chi^{2}$ test (or Fisher's exact test) for categorical measures were used. Unadjusted survival rates and survival curves were determined by Kaplan-Meier estimates. The univariate and multivariate risk analyses of mortality/HTX were performed using time-dependent Cox proportional hazards models. For these survival and risk analyses, patients with a Fontan takedown were excluded. A twosided $p$ value $<0.05$ was considered to indicate statistical significance.

\section{RESULTS}

Two hundred twenty-five patients met the inclusion criteria (figure 1). They were identified from 22 congenital heart centres (range 1-40 patients/centre). Failing Fontan surgery took place in the time era 1986-2012. See tables 1 and 2 for the baseline characteristics. Patients were on average aged 5.9 \pm 4.9 years when they either had Fontan completion or had a one-stage Fontan procedure. In total, 136 patients $(60.4 \%)$ had some form of APC, whereas the remainder had a total cavopulmonary connection (TCPC) $(n=89 ; 39.6 \%)$.

In absolute counts, the most prevalent indication was arrhythmia $(98 / 225$ patients $=43.6 \%$, table 3$)$. For 78 patients $(34.7 \%)$, the decision for surgery was based on only one indication. However, for the whole population, the combination of 2.0 \pm 0.97 indications led to failing Fontan surgery. Arrhythmia and RA dilatation were the main indications for Fontan conversion, while deteriorating FC and PLE were the main indications for HTX ( $p<0.001$, figure 2).

\section{Failing Fontan surgery}

Fontan takedown was performed in 38 patients (17\%), Fontan conversion in 137 patients $(61 \%$, ie, $13 \%$ conversion to a TCPC LT and $48 \%$ to a TCPC EC) and HTX in 50 patients (22\%). Two patients were successfully bridged to HTX by a paracorporeal ventricular assist device. Of all patients treated with Fontan conversion, 51.6\% had concomitant rhythm surgery (maze rhythm surgery). The cumulative occurrence of surgical interventions for failing Fontan increased over time $(\mathrm{p}=0.01$, see online supplementary figure S1). Yet, the distribution across the surgical groups did not change during the decades $(p=0.19$, see online supplementary figure S2).

The time interval between the initial Fontan procedure and the failing Fontan surgery was significantly shorter in the group referred for a Fontan takedown procedure $(0.6 \pm 1.9$ years) compared with patients who underwent HTX or Fontan conversion $(8.5 \pm 6.1$ years and $15.2 \pm 7.0$ years, respectively; $\mathrm{p}<0.001)$. Comparison of the three groups also revealed statistical differences for the following variables: primary diagnosis, the presence of heterotaxy, previous BDG, type of initial Fontan surgery, preoperative NYHA class, ventricular dysfunction, atrial rhythm disturbances, RA pressure, age at failing Fontan surgery, extracorporeal circulation time, ventilation time, intensive care unit stay, hospital stay and medication use (tables 1 and 2).

\section{Follow-up after Fontan takedown}

During a mean follow up (FU) of $6.7 \pm 6.7$ years (range $0-23.7$ years), 15 patients $(39.5 \%)$ died, of whom two-thirds $(10 / 15$ patients) in the first 30 postoperative days (ie, early mortality was $26.3 \%)$. After a mean period of $12.9 \pm 21.1$ months, four patients $(10.5 \%)$ underwent HTX after Fontan takedown with two patients alive at the end of follow-up. Two takedown patients $(5.3 \%)$ underwent subsequent TCPC LT operation after a mean period of $34.1 \pm 14.1$ months. A total of 17 patients $(44.7 \%)$ had reached the primary end point mortality/HTX at the end of follow-up (see online supplementary figure S3).

\section{Follow-up after Fontan conversion}

During a mean FU of $7.7 \pm 5.7$ years (range $0-24.7$ years), a total of 30 patients died (21.9\%). Thirty-six patients $(26.3 \%)$ reached the combined end point mortality/HTX. Early mortality was $15 / 137(10.9 \%)$. In seven patients $(5.2 \%)$, the Fontan conversion was followed by HTX after a mean period of 3.3 \pm 2.8 years. One of these seven patients died 19.1 years after HTX. The primary end point mortality/HTX $(n=36)$ occurred during 1000 patient-years follow-up (event rate 3.6/100 patientyears). Among the patients who survived Fontan conversion, $89 \%$ were in NYHA class I or II. 
Figure 1 Flowchart describing the surgical treatment for patients with failing Fontan $(n=231)$. HTX, heart transplantation; LT, lateral tunnel; EC, extracardiac conduit.

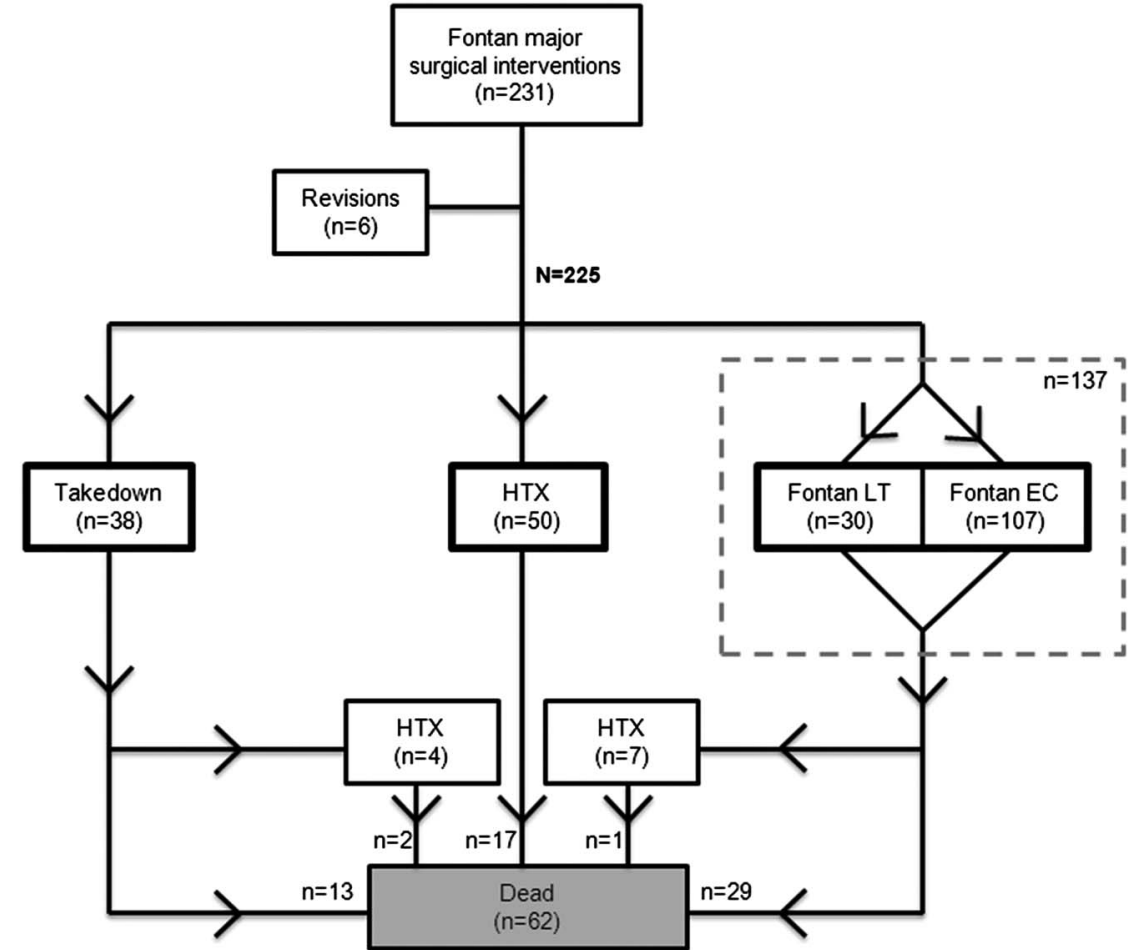

Within the 130 patients with an APC, patients with valveless APCs $(n=89)$ had better outcomes after Fontan conversion than those with a valve-containing APC $(n=41 ; p=0.04$, figure 3). However, patients in the latter group were on average $3.7 \pm 1.8$ years older $(\mathrm{p}=0.04)$. Event-free survival after Fontan conversion combined with MAZE rhythm surgery $(n=64 ; 51.6 \%)$ did not significantly differ from Fontan conversion without rhythm surgery $(n=60 ; 48.4 \%, p=0.57)$.

\section{Follow-up after HTX}

During a mean FU of 5.7 \pm 5.4 years (range: $0-22.2$ years), 17 patients (34\%) died. No patients underwent retransplantation. The mortality end point occurred during 287 patient-years follow-up (event rate 5.9/100 patient-years). Early mortality was $14 \%$ and in-hospital mortality was $20 \%$. Of all patients who underwent failing Fontan surgery, HTX patients had the longest extracorporeal circulation time $(289 \pm 169 \mathrm{~min})$ and hospital

Table 1 Baseline characteristics: demographics and medical history

\begin{tabular}{|c|c|c|c|c|c|}
\hline Characteristic & All $(n=225)$ & Conversion $(n=137)$ & Takedown $(n=38)$ & HTX $(n=50)$ & p Value \\
\hline Male sex, N (\%) & $118(52.4)$ & $69(50.4)$ & $18(47.4)$ & $31(62.0)$ & 0.29 \\
\hline Diagnosis, N (\%) & & & & & $<0.001$ \\
\hline Tricuspid atresia & $85(37.8)$ & $71(51.8)$ & $6(15.8)$ & $8(16.0)$ & \\
\hline DILV & $46(20.4)$ & $30(21.9)$ & $6(15.8)$ & $10(20.0)$ & \\
\hline Unbalanced (A)VSD & $21(9.3)$ & $5(3.6)$ & $10(26.3)$ & $6(12.0)$ & \\
\hline HLHS & $17(7.6)$ & $2(1.5)$ & $4(10.5)$ & $11(22.0)$ & \\
\hline PA/IVS & $17(7.6)$ & $11(8.0)$ & $2(5.3)$ & $4(8.0)$ & \\
\hline Other & $39(17.3)$ & $18(13.1)$ & $10(26.3)$ & $11(22.0)$ & \\
\hline Heterotaxy, N (\%) & $38(16.9)$ & $15(10.9)$ & $13(34.2)$ & $10(20.0)$ & 0.003 \\
\hline \multicolumn{6}{|l|}{ Surgical history, N (\%) } \\
\hline Pulmonary artery banding & $47(20.9)$ & $25(18.2)$ & $11(28.9)$ & $11(22.0)$ & 0.35 \\
\hline Blalock-Taussig shunt & $131(58.2)$ & $78(56,9)$ & $23(60.5)$ & $30(60.0)$ & 0.89 \\
\hline Bidirectional Glenn & $72(32.0)$ & $13(9.5)$ & $26(68.4)$ & $33(66.0)$ & $<0.001$ \\
\hline Age at initial Fontan, years $( \pm S D)$ & $5.9(4.9)$ & $6.2(4.8)$ & $4.6(2.9)$ & $6.2(6.1)$ & 0.18 \\
\hline Type of initial Fontan surgery, N (\%) & & & & & $<0.001$ \\
\hline Björk modification & $19(8.4)$ & $18(13.1)$ & $0(0.0)$ & $1(2.0)$ & \\
\hline APC without valve & $94(41.8)$ & $81(59.1)$ & $5(13.2)$ & $8(16.0)$ & \\
\hline APC with valve & $23(10.2)$ & $20(14.6)$ & $1(2.6)$ & $2(4.0)$ & \\
\hline TCPC LT & $45(20.0)$ & $18(13.1)$ & $12(31.6)$ & $15(30.0)$ & \\
\hline TCPC EC & $44(19.6)$ & $0(0.0)$ & $20(52.6)$ & $24(48.0)$ & \\
\hline
\end{tabular}

(A)VSD, (atrio)ventricular septum defect; APC, atriopulmonary connection; DILV, double inlet left ventricle; EC, extracardiac conduit; HLHS, hypoplastic left heart syndrome; HTX, heart transplantation; LT, lateral tunnel; PA/IVS, pulmonary atresia with intact ventricular septum; TCPC, total cavopulmonary connection. 


\section{Congenital heart disease}

Table 2 Preoperative and surgical variables (failing Fontan surgery)

\begin{tabular}{|c|c|c|c|c|c|}
\hline Characteristic & All $(n=225)$ & Conversion $(n=137)$ & Takedown $(n=38)$ & $\operatorname{HTX}(n=50)$ & $\mathrm{p}$ Value \\
\hline Age at failing Fontan surgery, years $( \pm S D)$ & $17.1(10.3)$ & $21.4(8.9)$ & $5.2(3.2)$ & $14.7(9.4)$ & $<0.001$ \\
\hline Time between Fontan completion and failing Fontan surgery, years $( \pm S D)$ & $11.2(8.3)$ & $15.2(7.0)$ & $0.6(1.9)$ & $8.5(6.1)$ & $<0.001$ \\
\hline NYHA class III/IV*, N (\%) & $112(55.2)$ & $45(36.3)$ & $22(73.3)$ & $45(91.8)$ & $<0.001$ \\
\hline$\geq$ Moderate AVV regurgitation, $\mathrm{N}(\%)$ & $55(24.4)$ & $29(21.2)$ & $10(26.3)$ & $16(32.0)$ & ns \\
\hline Moderate/poor LV function, N (\%) & $115(51.1)$ & $58(42.3)$ & $14(36.8)$ & $43(86.0)$ & $<0.001$ \\
\hline Atrial rhythm disturbances, $\mathrm{N}(\%)$ & $112(49.8)$ & $91(66.4)$ & 4 (10.5) & $17(34.0)$ & $<0.001$ \\
\hline RA pressure, mm Hg $( \pm \mathrm{SD})$ & $14.8(4.3)$ & $14.0(4.2)$ & $15.0(4.2)$ & $16.7(4.0)$ & 0.002 \\
\hline \multicolumn{6}{|l|}{ Medication use, N (\%) } \\
\hline Aspirin & $67(29.8)$ & $39(28.5)$ & $11(28.9)$ & $17(34.0)$ & $<0.001$ \\
\hline Coumadin & $117(52.0)$ & $79(57.7)$ & 7 (18.4) & $31(62.0)$ & $<0.001$ \\
\hline ACE-inhibitor & $90(40.0)$ & $47(34.3)$ & $7(18.4)$ & $36(72.0)$ & $<0.001$ \\
\hline$\beta$-Blocker & $43(19.1)$ & $35(25.5)$ & $0(0.0)$ & $8(16.0)$ & $<0.001$ \\
\hline Digoxin & $56(24.9)$ & $32(23.4)$ & $8(21.1)$ & $16(32.0)$ & 0.004 \\
\hline Sotalol & $29(12.9)$ & $25(18.2)$ & $1(2.6)$ & $3(6.0)$ & $<0.001$ \\
\hline Amiodarone & $47(20.9)$ & $42(30.7)$ & $2(5.3)$ & $3(6.0)$ & $<0.001$ \\
\hline ECC time, $\min ( \pm S D)$ & $197(119)$ & $173(89)$ & $175(86)$ & $289(169)$ & $<0.001$ \\
\hline Ventilation time, days $( \pm$ SD) & $5.4(11.7)$ & $3.1(4.7)$ & $11.8(22.9)$ & $7.5(12.3)$ & 0.001 \\
\hline ICU stay, days $( \pm$ SD) & $12.9(23.8)$ & $8.0(12.8)$ & $23.8(38.4)$ & $18.6(30.0)$ & $<0.001$ \\
\hline Hospital stay, days $( \pm S D)$ & $28.9(32.7)$ & $21.8(19.7)$ & $37.6(41.7)$ & $43.0(46.7)$ & $<0.001$ \\
\hline
\end{tabular}

${ }^{*}$ Available for 203 patients.

ACE, angiotension-converting enzyme; AVV, atrioventricular valve; ECC, extracorporeal circulation; HTX, heart transplantation; ICU, intensive care unit; LV, left ventricle; NYHA, New York Heart Association; ns, not significant; RA, right atrial.

stay (43.0 \pm 46.7 days). Among the patients who were discharged from the hospital $(\mathrm{n}=43), 85 \%$ were in NYHA class I or II at the end of follow-up.

\section{Risk analyses for mortality/HTX after failing Fontan surgery}

Mean follow-up after HTX or Fontan conversion was 6.9 \pm 5.4 years. In only 15 patients, the follow-up duration exceeded 15 years and for that reason the unadjusted survival curve was truncated at 15 years after failing Fontan surgery. Although the survival curves diverge in favour of FC patients, event-free survival was not statistically different $(\mathrm{p}=0.13$, figure 4$)$.

Among the 187 patients with either a Fontan conversion or HTX, the following characteristics were significantly associated with the primary end point: time interval between initial Fontan surgery and failing Fontan surgery (ie, more events in patients whose circulation start to fail within 10 years after initial Fontan), NYHA class III/IV and ventricular dysfunction (table 4). Multivariate analyses showed that patients with ventricular dysfunction have an increased risk of mortality/HTX $(p=0.009)$.

Table 3 Indications for failing Fontan surgery

\begin{tabular}{lc}
\hline Indication & Number (\%) \\
\hline Arrhythmia & $98(43.6)$ \\
Deteriorating functional class & $97(43.1)$ \\
Extreme RA dilatation & $87(38.7)$ \\
Obstruction & $47(20.9)$ \\
Protein losing enteropathy & $31(13.8)$ \\
Thrombus & $26(11.6)$ \\
AVV regurgitation & $18(8.0)$ \\
Pulmonary vein stenosis & $11(4.9)$ \\
Cyanosis & $12(5.3)$ \\
Systemic obstruction & $4(1.8)$ \\
Baffle leak & $4(1.8)$ \\
\hline
\end{tabular}

AVV, atrioventricular valve; RA, right atrial.
Within the group of Fontan patients with an APC, no specific treatment benefit could be determined after 15 years follow-up between FC and HTX $(p=0.80)$.

\section{DISCUSSION}

This multicenter, European observational study of failing Fontan patients is, to our knowledge, the largest in the world permitting analysis to compare different surgical strategies for a failing Fontan. We have shown that Fontan takedown has been used as a surgical strategy in the early postoperative phase after Fontan completion, whereas Fontan conversion or HTX were the most important surgical options in the long run. In

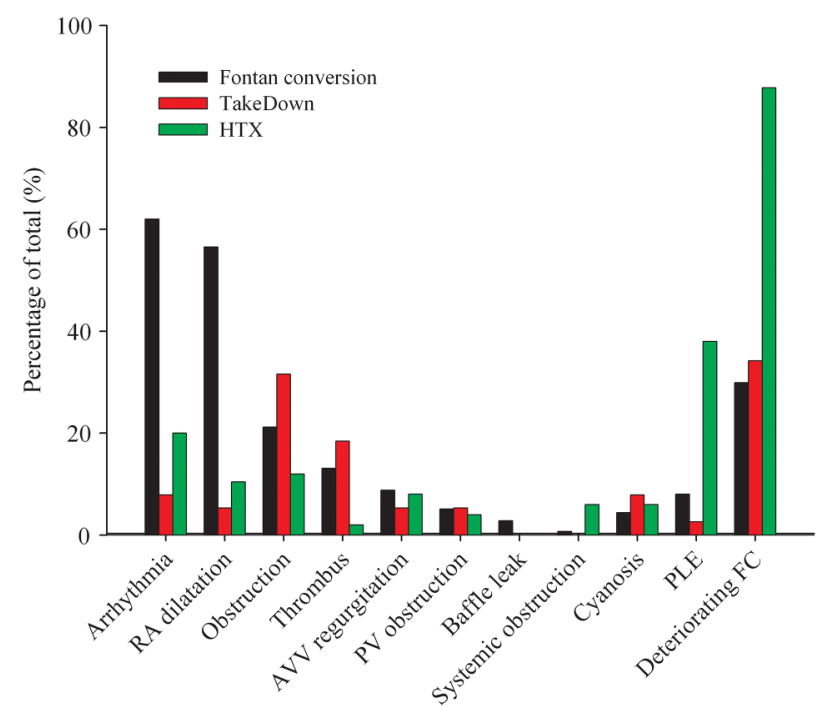

Figure 2 Indications for failing Fontan surgery. More than one indication is possible within the same patient. RA, right atrial; AVV, atrioventricular valve; PV, pulmonary vein; $\mathrm{PLE}$, protein losing enteropathy; FC, functional class. 


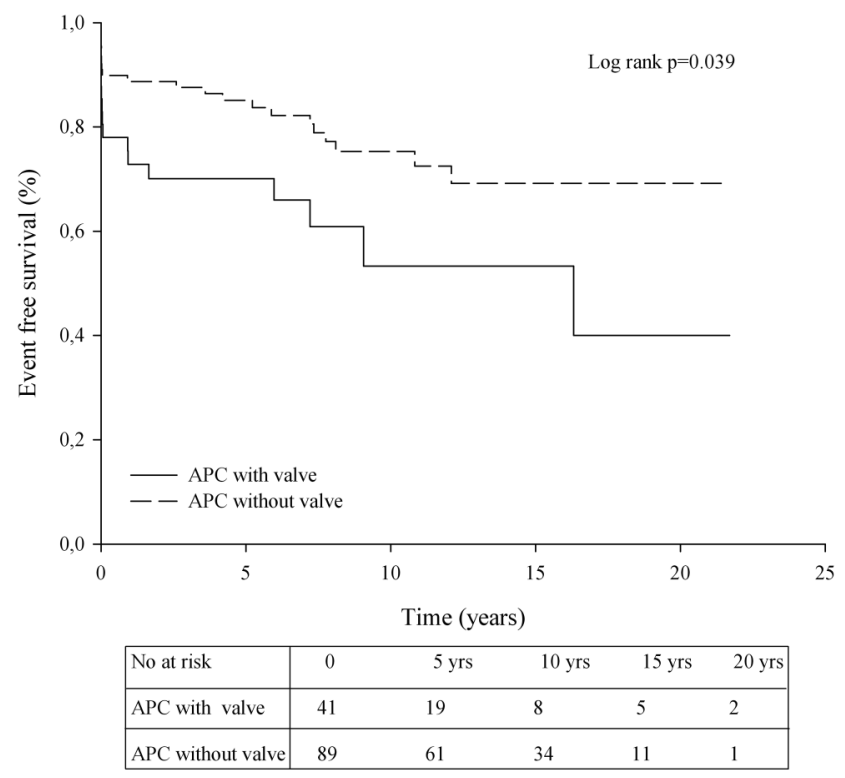

Figure 3 Kaplan-Meier plot showing the event-free survival for patients with an atriopulmonary connection (APC)-type Fontan $(n=130)$ according to the presence or absence of a valve-containing conduit. End points are mortality or heart transplantation. yrs, years.

comparison between the two latter strategies, no survival benefit could be identified, yet we have to realise that these groups are selected for severity of ventricular dysfunction. Generally, the ventricular function was much poorer in the HTX group as compared with the conversion group. Furthermore, a valvecontaining conduit is a risk factor for Fontan conversion in patients with APC with a failing Fontan circulation, the reason of which is currently subject to speculation.

Although survival has improved markedly in the past decades, ${ }^{3}$ Fontan patients are still at substantially increased risk of late morbidity and death as compared with the normal population. ${ }^{16}$ Presumably, the adult numbers of Fontan patients will

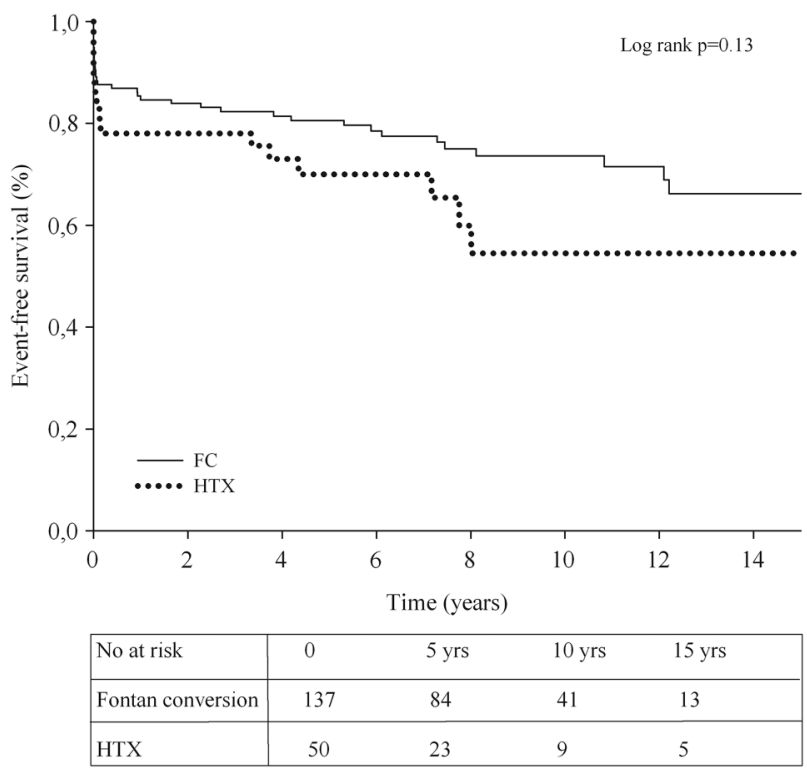

Figure 4 Kaplan-Meier plot showing the event-free survival after heart transplantation (HTX) $(n=50)$ or Fontan conversion $(n=137)$. Time of follow-up is truncated at 15 years. End points are mortality or (re-)HTX. FC, functional class; yrs, years.
Table 4 Univariate and multivariate analysis in failing Fontan patients $(n=187)$

\begin{tabular}{|c|c|c|c|c|}
\hline \multirow[b]{3}{*}{ Characteristic } & \multicolumn{4}{|c|}{ Mortality/HTX } \\
\hline & \multirow[b]{2}{*}{ N (\%) } & \multirow{2}{*}{$\begin{array}{l}\text { Univariate } \\
\text { p Value }\end{array}$} & \multicolumn{2}{|l|}{ Multivariate } \\
\hline & & & HR $(95 \% \mathrm{Cl})$ & $\begin{array}{l}p \\
\text { Value }\end{array}$ \\
\hline $\begin{array}{l}\text { Interval Fontan } \\
\text { completion-failing } \\
\text { Fontan surgery } \\
\text { (<10 years) }\end{array}$ & $26(26.6)$ & 0.049 & & ns \\
\hline NYHA class III/IV & $32(35.6)$ & 0.028 & & ns \\
\hline $\begin{array}{l}\text { Moderate/poor ventricular } \\
\text { function }\end{array}$ & $37(36.6)$ & 0.004 & 2.52 (1.26 to 5.03$)$ & 0.009 \\
\hline
\end{tabular}

increase by over $60 \%$ in the next decade and the proportion in NYHA FC III is expected to double. ${ }^{17}$ Unfortunately, a failing Fontan circulation represents a particularly complicated scenario for both patients and physicians. ${ }^{18}$ They are confronted with an insidiously deteriorating clinical situation, while there are no studies available that describe and compare treatment options. Given the overall young age of this population with impaired life expectancy, it is to be expected that a huge proportion of these patients will be candidates for failing Fontan surgery. In the current study, the complex nature of failing Fontan was confirmed since $65 \%$ of the failing Fontan patients had at least two indications that led to the decision to operate.

The current study demonstrated that Fontan takedown has primary been used as a bailout option in early Fontan failure, considering the short interval between Fontan completion and takedown surgery (ie, 7.2 months). This is in line with previous small case series $(n \leq 6)$, where Fontan takedown was accomplished in the early aftermath of Fontan completion. ${ }^{19}{ }^{20}$ The different characteristics of the Fontan takedown population ('early failing Fontan') precludes a fair comparison with Fontan conversion or HTX ('late failing Fontan') and therefore we reported the outcome of this strategy separately. Our data showed that mortality rates are very high $(40 \%$ after a mean follow-up of 6.7 years), especially in the first 30 days after Fontan takedown. Yet, the relative percentage of Fontan takedowns steadily decreased over time. This probably points to improved patient selection on the road towards Fontan completion. Whether Fontan takedown is a reasonable alternative for HTX or Fontan conversion in late failing Fontan remains to be elucidated.

Since the pioneering work of Mavroudis et al, ${ }^{21}$ Fontan conversion to the more energy-efficient extracardiac connection with concomitant arrhythmia surgery is the standard for patients with APC, especially those with atrial tachyarrhythmias. In their own single-centre series including 111 Fontan conversions, an early mortality rate of $0.9 \%$ was reported, ${ }^{22}$ but percentages up to $13 \%^{23}$ are described. In our study, early mortality was $11 \%$. Recently, a study in 39 patients following Fontan conversion reported 8 deaths (21\%) after a mean follow-up of 6 years. With a slightly longer mean follow-up (of 7.7 years), the current study demonstrated a similar mortality rate of $21 \%$.

We previously described the outcome after HTX in Fontan patients $(n=61)$, also including patients who initially were treated with Fontan conversion or Fontan takedown. ${ }^{24}$ In the current study, using an intention-to-treat analysis, we showed that during a mean FU of 5.7 years $34 \%$ died. Early mortality 
was high (20\%), but this is in accordance with an actuarial survival after HTX of $80 \%$ at 6 months in a large cohort derived from the Pediatric Heart Transplant Study database in the USA. $^{25}$

Perhaps the most compelling contribution of the current study is the possibility to compare outcomes of Fontan conversion and HTX. We now could provide evidence that survival between HTX and Fontan conversion does not significantly differ. Furthermore, we found that poor systemic ventricular function was a risk factor for death/HTX after failing Fontan surgery. Possibly, ventricular dysfunction is associated with poor general health status and high patient frailty in Fontan patients, which may affect survival after surgery. Finally, it appeared that valve-containing APCs are at increased risk for Fontan conversion. For patients with APC, there was no specific treatment benefit for Fontan conversion or HTX, but this finding needs to be interpreted cautiously due to the fact that within the 130 patients with an APC, 119 patients were treated with a Fontan conversion, while only 11 patients were treated with HTX. Nevertheless, these results may be of importance for future treatment algorithms in patients with failing Fontan.

Our findings should be evaluated in the context of several limitations. First of all, our study is limited by its observational cohort design, which may complicate the interpretation of the results, derived from four decades of data acquisition. Related to this point, decision making for the different procedures was based on the discretion of the treating physician(s) and not on certain treatment algorithms. The best way to control for treatment-selection bias is to conduct a randomised trial, but given the relatively rare syndrome of failing Fontan, the set up of such a trial is, unfortunately, an utopia. Hence, the three pathways are not mutually exclusive and we have to realise that the Fontan background is not identical for every patient (eg, conversion is not an option for patients following TCPC EC). Nevertheless, our dataset provides unique information on longterm outcomes. Second, in our study we evaluated the three most performed surgical treatments for failing Fontan. Despite encouraging results of other surgical interventions in the last years, for example, with ventricular assist devices, ${ }^{26}$ we analysed these alternatives not systematically. Finally, some variables that are known in clinical practice to have a profound effect on the

Key messages

What is already known on this subject?

The Fontan circulation is subject to gradual attrition ('Failing Fontan'). No data are available to compare outcome of the different surgical options to treat the failing Fontan circulation.

\section{What might this study add?}

Fontan takedown is generally performed at a short interval after Fontan completion with a high risk of mortality. Fontan conversion and heart transplantation (HTX) are the main treatment options for late Fontan failure with no difference in survival between the two techniques. Furthermore, we found that poor systemic ventricular function was a risk factor for death/HTX after failing Fontan surgery.

How might this impact on clinical practice? These results may add to the decision-making process for this growing subset of critically ill patients. choice of failing Fontan surgery (eg, the presence of systemic-to-pulmonary arterial or venovenous collateral flow, anthropomorphic characteristics of the patient and patient frailty) were not available for this analysis.

In conclusion, the syndrome of failing Fontan is the result of an inevitable and insidious attrition of the Fontan circulation. Fontan takedown has been used as a surgical strategy for a failing Fontan circulation in the early postoperative phase with high risk for mortality. There is no difference in survival after Fontan conversion or HTX. Hence, these groups are selected for ventricular dysfunction. In general, a late failing Fontan patient with a poor ventricular function is better off with an HTX, while a patient with preserved ventricular function can well be treated with conversion.

\section{Author affiliations}

${ }^{1}$ Department of Cardiology, University Medical Center Groningen, University of Groningen, Groningen, The Netherlands

${ }^{2}$ Department of Pediatric Cardiology, Beatrix Children's Hospital, University Medical Center Groningen, University of Groningen, Groningen, The Netherlands

${ }^{3}$ Technical University, German Heart Center Munich, Munich, Germany

${ }^{4}$ Department of Congenital Heart Disease, Centre Chirurgical Marie Lannelongue,

Paris, France

${ }^{5}$ Department of Cardiac Surgery, Catholic University Leuven, Leuven, Belgium

${ }^{6}$ Pediatric and Congenital Cardiovascular Surgery Unit, Department of Cardiac

Thoracic and Vascular Sciences, University of Padova, Padua, Italy

${ }^{7}$ Department of Thoracic and Cardiovascular Surgery, Rikshospitalet, Oslo University

Hospital, Oslo, Norway

${ }^{8}$ Johns Hopkins All Children's Heart Institute, All Children's Hospital and Florida

Hospital for Children, Saint Petersburg, Tampa, and Orlando, Florida, USA

${ }_{9}^{9}$ Johns Hopkins University, Baltimore, Maryland, USA

${ }^{10}$ Hospital for Children and Adolescents, University of Helsinki, Helsinki, Finland

${ }^{11}$ Children's Heart Centre, The Queen Silvia Children's Hospital, Gothenburg,

Sweden

${ }^{12}$ Clinic for Cardiovascular Surgery, University Hospital Zurich, Zurich, Switzerland

${ }^{13}$ Leiden University Medical Center, Leiden, The Netherlands

${ }^{14}$ Academic Medical Center, Amsterdam, The Netherlands

${ }^{15}$ Department of Cardio-Thoracic Surgery, University Hospital of Copenhagen,

Copenhagen, Denmark

${ }^{16}$ National Institute of Cardiovascular Disease, Children's Heart Centre Slovak

Republic, Bratislava, Slovakia

${ }^{17}$ Department of Pediatric Cardiac Surgery, Children's Heart Center, Motol University Hospital, Prague, Czech Republic

${ }^{18}$ Division of Cardiac Surgery, Cliniques Universitaires Saint-Luc, Brussels, Belgium

${ }^{19}$ National Heart Hospital Sofia, Sofia, Bulgaria

${ }^{20}$ Department of Cardiovascular Surgery, Center for Congenital Heart Surgery,

University Hospital Bern, Bern, Switzerland

${ }^{21}$ German Pediatric Heart Centre, Asklepios Clinic Sankt Augustin, Sankt Augustin, Germany

${ }^{22}$ Department of Cardiothoracic Surgery, Hospital de Santa Marta, Lisbon, Portugal

${ }^{23}$ Department of Congenital and Paediatric Cardiac Surgery and Cardiology, Riuniti Hospital, Ancona, Italy

${ }^{24}$ Athens Heart Surgery Institute, Athens, Greece

${ }^{25}$ Department of Pediatric, Congenital Heart Surgery at IASO Children's Hospital,

Athens, Greece

${ }^{26}$ Department of cardiothoracic surgery, University Medical Center Groningen,

University of Groningen, Groningen, The Netherlands

${ }^{27}$ Dipartimento Medico-Chirurgico di Cardiologia Pediatrica, Ospedale Pediatrico

Bambino Gesù, Roma, Italia

Twitter Follow Harald Lindberg at @Noharald and Tjark Ebels at @tjarkebels

Contributors All authors included on the submitted paper fulfil the criteria of authorship: (1) substantial contributions to the acquisition of data; (2) drafting the work or revising it critically for important intellectual content; (3) final approval of the version published; (4) agreement to be accountable for all aspects of the work in ensuring that questions related to the accuracy or integrity of any part of the work are appropriately investigated and resolved. In addition, JPvM, DW and TE made substantial contributions to the conception or design of the work and analysis or interpretation of data.

Competing interests None declared.

Ethics approval Local Institutional Review Boards.

Provenance and peer review Not commissioned; externally peer reviewed. 
Data sharing statement Unpublished data are available for further analysis for the whole author group by mutual agreement.

\section{REFERENCES}

1 Fontan F, Baudet E. Surgical repair of tricuspid atresia. Thorax 1971;26:240-8.

2 Kreutzer G, Galindez E, Bono H, et al. An operation for the correction of tricuspid atresia. J Thorac Cardiovasc Surg 1973;66:613-21.

3 Wolff D, van Melle JP, Ebels T, et al. Trends in mortality (1975-2011) after one- and two-stage Fontan surgery, including bidirectional Glenn through Fontan completion. Eur I Cardiothorac Surg 2014;45:602-9.

4 Khairy P, Poirier N, Mercier LA. Univentricular heart. Circulation 2007;115:800-12.

5 Elder RW, Parekh S, Book WM. More on hepatocellular carcinoma after the Fontan procedure. N Engl J Med 2013;369:490.

6 Mondésert B, Marcotte $\mathrm{F}$, Mongeon $\mathrm{FP}$, et al. Fontan circulation: success or failure? Can J Cardiol 2013;29:811-20.

7 Deal BJ, Jacobs ML. Management of the failing Fontan circulation. Heart 2012;98:1098-104.

8 DeLeon SY, Ilbawi MN, Idriss FS, et al. Persistent low cardiac output after the Fontan operation. Should takedown be considered? I Thorac Cardiovasc Surg 1986:92:402-5.

9 de Leval MR, Kilner P, Gewillig M, et al. Total cavopulmonary connection: a logical alternative to atriopulmonary connection for complex Fontan operations. Experimental studies and early clinical experience. I Thorac Cardiovasc Surg 1988;96:682-95.

10 Marcelletti C, Corno A, Giannico S, et al. Inferior vena cava-pulmonary artery extracardiac conduit. A new form of right heart bypass. J Thorac Cardiovasc Surg 1990;100:228-32.

11 Carey JA, Hamilton JR, Hilton CJ, et al. Orthotopic cardiac transplantation for the failing Fontan circulation. Eur J Cardiothorac Surg 1998;14:7-13; discussion 13-14.

12 Murtuza B, Dedieu N, Vazquez A, et al. Results of orthotopic heart transplantation for failed palliation of hypoplastic left heart. Eur J Cardiothorac Surg 2013;43:597-603.

13 De Vadder K, Van De Bruaene A, Gewillig M, et al. Predicting outcome after Fontan palliation: a single-centre experience, using simple clinical variables. Acta Cardiol 2014;69:7-14.
14 Hosein RB, Clarke AJ, McGuirk SP, et al. Factors influencing early and late outcome following the Fontan procedure in the current era. The 'Two Commandments'? Eur $J$ Cardiothorac Surg 2007;31:344-52; discussion 353.

15 Liu VJ, Yong MS, d'Udekem Y, et al. Outcomes of atrioventricular valve operation in patients with Fontan circulation. Ann Thorac Surg 2015;99:1632-8.

16 Diller GP, Giardini A, Dimopoulos K, et al. Predictors of morbidity and mortality in contemporary Fontan patients: results from a multicenter study including cardiopulmonary exercise testing in 321 patients. Eur Heart J 2010;31:3073-83.

17 Coats L, O'Connor S, Wren C, et al. The single-ventricle patient population: a current and future concern a population-based study in the North of England. Heart 2014;100:1348-53.

18 Rychik J, Goldberg DJ. Late consequences of the Fontan operation. Circulation 2014;130:1525-8.

19 lyengar AJ, Winlaw DS, Galati JC, et al. Trends in Fontan surgery and risk factors for early adverse outcomes after Fontan surgery: the Australia and New Zealand Fontan Registry experience. J Thorac Cardiovasc Surg 2014;148:566-75.

20 Murphy MO, Glatz AC, Goldberg DJ, et al. Management of early Fontan failure: a single-institution experience. Eur J Cardiothorac Surg 2014;46:458-64.

21 Mavroudis C, Backer CL, Deal BJ, et al. Fontan conversion to cavopulmonary connection and arrhythmia circuit cryoablation. I Thorac Cardiovasc Surg 1998; 115:547-56.

22 Mavroudis C, Deal BJ, Backer CL, et al. J. Maxwell Chamberlain Memorial Paper for congenital heart surgery. 111 Fontan conversions with arrhythmia surgery: surgical lessons and outcomes. Ann Thorac Surg 2007;84:1457-65.

23 Takahashi K, Fynn-Thompson F, Cecchin F, et al. Clinical outcomes of Fontan conversion surgery with and without associated arrhythmia intervention. Int J Cardiol 2009;137:260-6.

24 Michielon G, van Melle JP, Wolff D, et al. Favourable mid-term outcome after heart transplantation for late Fontan failure. Eur J Cardiothorac Surg 2015;47:665-71.

25 Bernstein D, Naftel D, Chin C, et al., Pediatric Heart Transplant Study. Outcome of listing for cardiac transplantation for failed Fontan: a multi-institutional study. Circulation 2006;114:273-80.

26 Almond CS, Morales DL, Blackstone EH, et al. Berlin Heart EXCOR pediatric ventricular assist device for bridge to heart transplantation in US children. Circulation 2013;127:1702-11. 


\section{Heart Surgical options after Fontan failure}

Joost $P$ van Melle, Djoeke Wolff, Jürgen Hörer, Emre Belli, Bart Meyns, Massimo Padalino, Harald Lindberg, Jeffrey P Jacobs, Ilkka P Mattila, Håkan Berggren, Rolf M F Berger, Rene Prêtre, Mark G Hazekamp, Morten Helvind, Matej Nosál, Tomas Tlaskal, Jean Rubay, Stojan Lazarov, Alexander Kadner, Viktor Hraska, José Fragata, Marco Pozzi, George Sarris, Guido Michielon, Duccio di Carlo and Tjark Ebels

Heart 2016 102: 1127-1133 originally published online April 13, 2016 doi: 10.1136/heartjnl-2015-309235

Updated information and services can be found at: http://heart.bmj.com/content/102/14/1127

\section{These include:}

References This article cites 26 articles, 14 of which you can access for free at: http://heart.bmj.com/content/102/14/1127\#BIBL
Email alerting service
Receive free email alerts when new articles cite this article. Sign up in the box at the top right corner of the online article.

Topic
Collections

Articles on similar topics can be found in the following collections

Congenital heart disease in adult patients (87)

Epidemiology (3691)

Drugs: cardiovascular system (8732)

Interventional cardiology (2910)

\section{Notes}

To request permissions go to:

http://group.bmj.com/group/rights-licensing/permissions

To order reprints go to:

http://journals.bmj.com/cgi/reprintform

To subscribe to BMJ go to:

http://group.bmj.com/subscribe/ 